\title{
How to Promote Interactions Teacher/Students During Confinement Period?
}

\author{
Natacha Duroisin ${ }^{1}$ \\ ${ }^{1}$ Teacher Training School, University of Mons, Belgium \\ Correspondence: Natacha Duroisin, Teacher Training School, University of Mons, Belgium.
}

Received: November 24, 2020

Accepted: December 21, 2020

Online Published: December 30, 2020

doi:10.20849/jed.v4i3.845

URL: https://doi.org/10.20849/jed.v4i3.845

\begin{abstract}
Since 13 March 2020, the establishments in French-speaking Belgium had to offer their distance lessons to curb the spread of the coronavirus (Covid-19). If the universities have material, technological and human resources to offer distance learning to students since several years, the confinement measures have however led the teachers to reorganize their courses started face-to-face by using numeric tools. This article pursues several objectives. On the one hand, it describes a teaching experience report based on the use of the podcast during a course in psychological and educational cursus. On the other hand, based on student's responses to a questionnary, it highlights the advantages and limits of using the podcast during the confinement period. Finally, this article aims to help teachers choose the digital device that corresponds to these pedagogical expectations in a distance education context.
\end{abstract}

Keywords: interactions, podcast, collaborative podcast, Covid-19, distance learning, verbatims, qualitative survey, teacher training

\section{Introduction}

Since 13 March 2020, face-to-face classes have been suspended in French-speaking Belgian universities (Communication from the Council of French-speaking Rectors of March 12, 2020 (Note 1)) to curb the spread of the coronavirus (Covid-19). From that date, higher education students have therefore been required to follow distance learning courses and direct interactions and verbal contacts between students and teachers are less frequent. By this situation, it follows that written works, including group works, were imposed more massively to students and that teachers most often give written feedback on these works (Caron, 2020). To overcome this situation and promote verbal exchanges between students and between students and teacher, podcasting appeared to be one of the interesting tools to use (Issa, Isaias \& Issa, 2014; Fernandez et al., 2015 ; Chaikovska, 2020).

The course concerned by the experience teaching related in this paper is titled "Preparatory course for school life" in psychological and educational cursus, which one takes the form of Practical Task (PT). This PT was to be organized face-to-face initially, but the start of the confinement linked to the Covid-19 health crisis led to reorganizing this course by using a digital tool. Two different uses of the same podcasting tool have been proposed. First, in group, the students were led to use collaborative podcasting. Then, the teacher used the podcast to provide feedback to the groups. The two uses of the podcast are discussed in this article. The advantages and disadvantages relating to the two uses of the podcast are discussed in this article, on the basis of a questionary which was completed by each group of students who used the podcast during the confinement period. The podcasting term comes from the combination of the iPod term (that is, the digital music player developed by Apple) and the broadcast term (Robinson \& Ritzko, 2009). A podcast is an audio and/or video file published on the Internet and broadcast via a syndication feed or an URL on a computer or mobile medium for direct listening or subsequent viewing (Copley, 2007).

A review of the literature written by Kay (2012) highlights several uses of the podcast in education. One of this is an autonomous use of the podcast. This is the most frequently encountered usage that corresponds to the situation where the podcast is made available as additional support for the face-to-face course and the course notes provided by the teacher. The student freely uses this support as part of a remediation or personal enrichment. One other is an integrated use of the podcast. The use of this podcast use is rather a starting point for learning, prompting questions and reflections which will lead to initiating individual or collaborative activities to reinvest the content discovered in the podcast. A third use of podcasting can also be found in the literature. Mainly used in the musical field, the podcast can be a collaborative creation tool (Ruthmann, 2007). This rare use of podcasting makes it possible, on 
the one hand, to respond to the field constraints imposed by confinement and, on the other hand, to consider formative evaluation by responding to the needs and requests of students.

If the advantages of podcasts (simple and fast way to distribute multimedia content, content accessible at any time and in any place...) are regularly highlighted by authors (i.e. Temperman \& De Lièvre, 2011), Chan, Chi \& Chin (2011) related that there is still few research into students' perceptions of and attitudes towards this device. This article describes a distance teaching experience through collaborative use of the podcast.

\section{Method}

\subsection{Course Description}

The teaching experience, described in this article, concerns a course given to around a hundred future teachers in the second cycle of secondary education (ISCED level 3 - International Standard Classification of Education) at the University of Mons in Belgium. This course spreads over a quadrimester started in Februaryand ended in May, by the delivery of a collaborative written work. At the end, student's groups must be able to take a critical and documented look at organizational aspects specific to secondary schools and thatgo beyond the teaching / learning activities which take place in the classroom (class council, participation, school project, etc.).

In practice, two face-to-face lessons were given before confinement period. Following the confinement measures, the teacher reorganized the PT and offered the students to use a digital solution to do the group work. After the delivery of the definitive work, each group of students who used the podcast was submitted to a questionary allowing to highlight the advantages and limits of using the collaborative podcast during the confinement period. The main steps of the course are detailled in Figure 1.

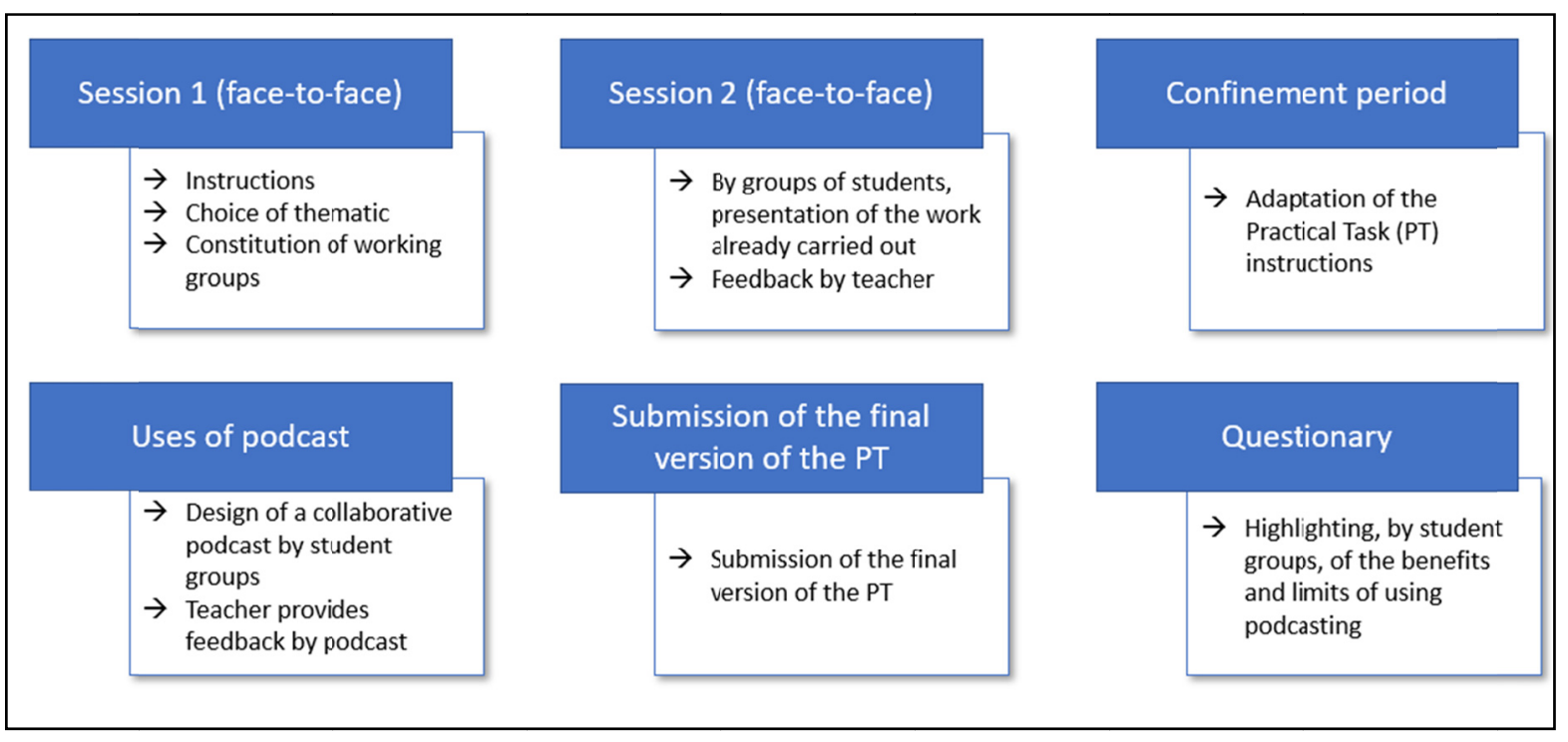

Figure 1. Main steps of the course

During the first session, in February, the Practical Task instructions are provided (Table 1, left column) and student groups are formed. First, students must select a theme related to school life. Secondly, they must problematize this thematic and define a few questions based on the literature. Following this session, students can make the first contacts in educational or extracurricular establishments in order to document their initial problematic and answer questions.

During the second course session, on March, the student groups presented the chosen thematics and the problematics associated. Personalized feedback was provided by the teacher to each member of the groups in order to best guide the students in the pursuit of their work.

As the confinement had been declared in Belgium from March 14, 2020, the third course could not be given face-to-face and it was difficult for some students to carry out visits and interviews in (peri-) school establishments, such as initially planned. Taking into account the circumstances and constraints related to confinement, the difficulties of some students to work for the university at home, the distinct advancements of each group in the 
work already started and taking care not to harm the students who had already done well progress, new instructions concerning the production expected for the PT were provided to the students (Table 1, right column). The use of podcasting was preferred to exchange by videoconferences for several reasons. On the one hand, several students -workers and parents for some- expressed their difficulties in being connected synchronously at a determined time of the day (all the members of the group connected at the same time), which then made almost impossible to share feedback for all groups. On the other hand, it would have been unrealistic for the teacher to attend the remote presentation of all group works at different time slots and to imagine that the members of other teams could also take part in presentations to benefit from comments made to other students. Regarding the possibility of exchanges by e-mail between groups of students and teacher, if these allow to respond punctually to certain specific questions (which is already possible via the Forum created on Moodle), these e-mails don't allow the teacher to understand the context of the work and the associated questions. In addition, the objective was to avoid a written entry on the part of the students (time-consuming, sometimes insufficiently detailed and / or more difficult for students to start at the start or in the workplace especially when questions are still very numerous).

An asynchronous solution (given the unavailability of some students at defined time slots), free, collaborative which allows the teacher to become aware of the work carried out/planned/in progress for each group of students had to be found (remember that the chosen themes and problems differ from one group of students to another, making the teacher's task even more complex). This consisted of using podcasting as a tool for creation, dissemination and formative evaluation. To do this, the podcast was used in two stages. First, as a collaborative tool: this is called a collaborative podcast. Then, as a tool for the delivery of feedback by the teacher: this is called podcast feedback (autonomous use for evaluation's purposes).

Table 1. Evolution of the practical task instructions

Writing a collaborative written work ( 3 to 4 students per group) of 15 to 20 pages on a theme (at choice) of school life.

Initially, the practical work is expected to include ;

- a collective part (introduction/thematic-problematic) (3 pages) ;

- an individual part (description of the schools and identification of the actors interviewed/transcription of the interviews and use of "verbatims" to discuss/respond to the initial problem) (3 pages);

- a collective (discussion/conclusion/bibliography/appendices) pages)
Writing of a collaborative written work (3 to 4 students per group) of 9 to 11 pages on a theme (at choice) of school life.

After reviewing the instructions, the practical work is expected to include :

- a collective part where the introduction/thematic is developed in the form of problematic in 1 page including min. three scientific and/or legal legal references and/or from professional journals to document the chosen issue)

- an individual part of two page (two pages/student)

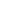

- a collective part where the discussion and the conclusion is developed, the objective of which is the pooling of the individual parts in connection with the initial problem (two pages)

\subsection{Podcasting as Way of Interactions Between Students and Between Students and Teacher}

The proposed solution was the production of two podcasts : a collaborative podcast made between students and a podcast made by the teacher to provide feedback.

Podcasts are produced using the free ANCHOR@ application. This application is available on AppleStore and PlayStore, for use on smartphones, and can also be downloaded from the Internet from a computer or tablet. This application only requires a microphone (the one originally available on the device used). The application allows to work asynchronously (it is not necessary for students using the application to be connected at the same time on their smartphone / computer / tablet) to make the collaborative podcast, so everyone can work on it when they have an occasion. You shouldn't know how to master the audio editing tools because the application allows you to easily compile the individual audio parts of each students by moving and directly reorganizing the elements recorded by 
each one. An image (eg presentation slide) can be directly integrated into the podcast. Finally, as soon as it is finished, the podcast can be broadcast via an URL obtained directly via the application. The URL is then placed on the online course supported by Moodle so that all students takes read it and that the teacher becomes aware of it and can, by return of podcast, deliver his formative evaluation.

\section{Results of the Questionary}

After the delivery of the definitive work, each group of students ( $\mathrm{N}$ groups $=18$ ) who used the podcast was submitted to a questionary. The first part of this questionary asks students to highlight the advantages and limits of using the collaborative podcast during the confinement period. The second part questions the students on the benefits and limits perceived of the use of the podcast by the teacher to deliver feedback.

\subsection{Benefits and Limitations of Collaborative Podcasting Perceived by Students}

Responding to the questionnaire, students described several advantages of using podcasting. These advantages as well as the associated verbatims are listed in Table 2.

Table 2. Benefits of collaborative podcasting

\begin{tabular}{|c|c|}
\hline \multirow[t]{6}{*}{ Time saving } & $\begin{array}{l}\text { "One of the strong points of the podcast is speed. No need to take time to write } \\
\text { down all our remarks questions "(group 3) }\end{array}$ \\
\hline & "It is sometimes easier to convey an idea orally rather than in writing" (group 3) \\
\hline & "We can transmit more information via the application than in writing" (group 5) \\
\hline & $\begin{array}{l}\text { "[It] allowed me to go straight to the point it allowed me not to waste my time } \\
\text { writing" beautiful sentences "" (group } 8 \text { ) }\end{array}$ \\
\hline & $\begin{array}{l}\text { "It takes less time to speak by explaining than to write the same amount of } \\
\text { information" (group 10) }\end{array}$ \\
\hline & "Sometimes it is easier to formulate your ideas orally than in writing" (group 12) \\
\hline \multirow{3}{*}{$\begin{array}{l}\text { Increasing and precision in } \\
\text { the number of information } \\
\text { transmitted }\end{array}$} & "Have the intonation of the person" (group 6) \\
\hline & "Allowing to present may be more detailed than it would be in writing" (group 6) \\
\hline & $\begin{array}{l}\text { "It also allows us to have oral explanations. Ability to play on voice modulation } \\
\text { and intonation to, for example, emphasize elements. We also had the possibility } \\
\text { of using written support, which is very positive, in my opinion "(group 13) }\end{array}$ \\
\hline Use of a current support & "We use ITC, it's more modern than paper" (group 2) \\
\hline Improvement of oral skills & "We practice orally" (group 7) \\
\hline Easier teamwork & "Easier to coordinate in group because it is done online" (group 9) \\
\hline Stress reduction & $\begin{array}{l}\text { "The advantage is that students can take the time to prepare their work [before } \\
\text { recording] and also decrease the stress" (group 11) }\end{array}$ \\
\hline
\end{tabular}

By answering the questionary, the students also highlighted several limits relating to the use of collaborative podcasting. These limits and the associated verbatims are listed in Table 3.

Table 3. Limitations of collaborative podcasting

Additional workload $\quad$ "In order to collect and structure our ideas, we first put everything in writing and
then read the text aloud for the podcast (additional workload)" (group 1)
"If we have a new question to ask we must all start again" (group 3)
"For my part, I had to try it several times before being satisfied with what I was
saying. Contrary to a written response where it is enough to erase what is wrong,
orally, an error is synonymous with a return to zero "(group 6)
"I find that it takes more time than a written assessment" (group 7)
"Maybe more time-consuming in terms of time (time to get used to the tool, to"


prepare "too well") (group 9)

"You must have a fairly correct oral expression from the first recordings otherwise it takes more time than the same amount of information written down" (group 11)

Getting started with the "You have to take the software in hand. (...) This can cause difficulties. We are application not all equal when it comes to digital tools "(group 2)

Loneliness if technical "The lack of immediate interaction in case of technical problem" (group 9) problems

Podcast's terms of use "With the health crisis, not everyone had the opportunity to record the podcast in a quiet location" (group 13)

\subsection{Benefits and Limitations of Podcasting to Provide Feedback}

Responding to the questionnaire, students described several advantages of using podcasting for to delivered feedback by teacher. These advantages as well as the associated verbatims are listed in Table 4.

Table 4. Benefits of podcasting to provide feedback

Impression of clearer, "It is clear and in addition you answered more by anticipating our possible future
$\begin{aligned} & \text { concise and complete } \\ & \text { feedback }\end{aligned}$
"We also have a more complete feedback" (group 5)
"Clear, concise" (group 15)

Feeling of proximity, "It's more user-friendly than an email or a text, it's closer to face-to-face personalization of feedback. The message gets better. The mail gives by its form a very formal side feedback, importance of to the exchange. Here it got a little more informal" (group 2)

intonation, conviviality

"The message was more" personal "than it would have been in writing, the intonation of your voice plays a lot to understand your remarks (better interpretation)" (group 4)

"Listening to you is much more pleasant and more personal than reading a written review. We also have a more complete return" (group 5)

"Because it is less impersonal than in writing and in the case of long feedbacks like here, it was much more pleasant than having the same quantity of elements in written format" (group 6)

"Your dynamic voice made it possible not to relax attention. Reading documents constantly causes attention to decrease" (group 8)

"It is always better to hear the intonation of voices in order to feel the intention of the Phrase" (group 16)

Data conservation and "This also allowed us to consult the feedback for the other groups" (group 12) consultation by students of podcasts intended for other groups

\subsection{Limits of the Podcast Produced by the Teacher to Provide Feedback}

By answering the questionary, the students also highlighted several limits relating to the use of podcasting by teacher for to delivery feedback. These limits and the associated verbatims are listed in Table 5. 
Table 5. Limitations of podcasting to provide feedback

\begin{tabular}{ll}
\hline $\begin{array}{l}\text { Difficulty finding } \\
\text { information quickly }\end{array}$ & $\begin{array}{l}\text { "Because it is necessary to listen to the feedback each time to find a specific } \\
\text { passage of the comment, when it's written, you can fly over the text and quickly } \\
\text { find the information you are looking for" (group 17) }\end{array}$ \\
\hline $\begin{array}{l}\text { Difficulty to analyze } \\
\text { feedback }\end{array}$ & $\begin{array}{l}\text { "It was quick to listen to but I find it more difficult to analyze each comment } \\
\text { individually" (group 18) }\end{array}$ \\
\hline
\end{tabular}

\section{Conclusion}

The health crisis is impacting university students by depriving them of certain interactions with other students and their teachers. This experience shows that a certain use of the podcast makes it possible to reduce isolation and strengthen interactions between individuals. To do this, in addition two more classical modes linked for using the podcast (stand-alone use and integrated use, cf. Kay, 2012), a third mode, traditionally linked to the artistic field, characterized by collaborative use, can be used at educational purposes.

The teaching experience described in this article brings along additional light on the use that can be made of this device, collaborative podcast in particular, for teaching-learning in the context of distance training. While some advantages of podcast use have already been noted in the literature (cf. Temperman \& De Lièvre, 2009 ; Issa, Isaias \& Issa, 2014), others advantages of collaborative of podcast use have been highlighted by the students during this study (time saving, increasing and precision in the number of information transmitted versus paper indications, stress reduction, feeling of proximity, importance of intonation, conviviality ...). In parallel with these advantages, drawbacks have also been noted when using the podcast by students (additional workload, difficulty finding information quickly, podcast's terms of use) and the teacher to delivered feed-back.

Although it includes student verbatim's to support the statements made here, this study has several limitations. First of all, it concerns a relatively small sample made up of around sixty students (divided into 18 groups). Then, this study is very contextualized as it is based on a teaching experience within the framework of a course given to future teachers in the second cycle of secondary education.

In conclusion, if the choice of a digital device must inevitably depend on the objectives pursued during the lessons (Duroisin, Temperman \& De Lièvre, 2015), it is also important for the teacher to be aware of the advantages and disadvantages perceived by the use of the digital tool by the students. As Chan, Chi \& Chin (2011) indicate, there is still comparatively little research into students' perceptions of and attitudes towards this device. In this contexte, this article was written to help teachers make the wisest choices of digital device during confinement period (or outside of this).

\section{References}

Caron, P. A. (2020). Ingénierie dispositive et enseignement à distance au temps de la COVID 19. Distances Et Médiations Des Savoirs, 30. https://doi.org/10.4000/dms.5211

Chaikovska, O. (2020). The impact of podcasts designed through audacity on improving grammar skills. Open Educational E-Environment of Modern University, (8), 1-7. https://doi.org/10.28925/2414-0325.2020.8.1

Chan, M., Chi, W., \& Chin, N. (2011). Students' perceptions of and attitudes towards podcast-based learning : A comparison of two language podcast projects. Electronic Journal of Foreign Language Teaching, 8(1), 312-335.

Copley, J. (2007). Audio and video podcasts of lectures for campus-based students: production and evaluation of student use. Innovations in Education and Teaching International, 44(4), 387-399. https://doi.org/10.1080/14703290701602805

Duroisin, N. (2020). Le podcasting collaboratif, un outil pour l'évaluation formative à distance. Journal International de Recherche en Éducation et Formation (Numéro Hors-Série), 1, 121-130.

Duroisin, N., Temperman, G., \& De Lièvre, B. (2015). Restrict or share the use of the interactive whiteboard? The consequences on the perception, the learning processes and the performance of students within a learning sequence on dynamic geometry. The Turkish Online Journal of Educational Technology, 14(2), 144-154.

Fernandez, V., Simo, P., \& Sallan, J. (2015). Podcasting: A new technological tool to facilitate good practise in higher education. Computers \& Education, 53(2), 385-392. https://doi.org/10.1016/j.compedu.2009.02.014 
Issa, T., Isaias, P., \& Issa, T. (2014). Does 'MP3' Audio Feedback Enhance Students' Learning Skills? An International Case Study. The International Journal of Learning, 19, 15-28. https://doi.org/10.18848/1447-9494/CGP/v19/58836

Kay, R. (2012). Exploring the use of video podcasts in education: A comprehensive review of the literature. Computers in Human Behavior, 28(3), 820-831. https://doi.org/10.1016/j.chb.2012.01.011

Robinson, S., \& Ritzko, J. (2009). Podcasts in Education: What, Why and How?. Proceedings of the Academy of Educational Leadership, 14(1), 38-43.

Temperman, G., \& De Lièvre, B. (2009). Développement et usage intégré des podcasts pour l'apprentissage. Distances et Savoirs, 7(2), 179-190. https://doi.org/10.3166/ds.7.179-190

\section{Note}

Note 1. http://www.cref.be/communication/

\section{Copyrights}

Copyright for this article is retained by the author(s), with first publication rights granted to the journal.

This is an open-access article distributed under the terms and conditions of the Creative Commons Attribution license (http://creativecommons.org/licenses/by/4.0/). 